\title{
A jurisdição civil coletiva e a tutela constitucional no meio ambiente
}

\author{
The collective civil jurisdiction and the constitutional guarantee in the environment
}

\section{Luciana Uchôa Ribeiro Lur ${ }^{1}$}

1 Advogada, Mestre em Direito Ambiental e Políticas Públicas pela Universidade Federal do Amapá (UNIFAP). Especialista em Direito Constitucional Aplicado pelo Complexo Damásio de Jesus (CDJ). Bacharel em Direito pela Faculdade Estácio SEAMA. Vice-Presidente da Comissão de Meio Ambiente e Recursos Hídricos da Ordem dos Advogados do Brasil Seccional Amapá (OAB/AP). Professora de Direito Ambiental e Direito Processual Ambiental, Consultora, Parecerista e Palestrante da área ambiental. E-mail: lucianaur@hotmail.com

RESUMO: 0 presente trabalho tem por tema a proteção constitucional do meio ambiente e a jurisdição civil do dano ambiental difuso e coletivo. Em primeiro momento o trabalho analisa a proteção direcionada pela Constituição Federal de 1988 para o meio ambiente, considerando este como um direito fundamental inserido na terceira dimensão de direitos, essencial a manutenção de vida do homem e dos demais seres vivos. Em segundo momento investiga as teorias da responsabilidade civil ambiental sem obstar as formas e destinações das sanções civis. E, por fim analisa a jurisdição civil coletiva sob o viés da ação civil pública em defesa do meio ambiente. A pesquisa é estritamente bibliográfica, pois, terá como base metodológica o estudo de doutrina, legislação, e jurisprudência, como fontes do direito, perfazendo abordagem qualitativa, com método científico indutivo, e do tipo exploratória Os processos de jurisdição civil coletiva e difusa ambiental sob as bases constitucionais constituem o mérito da pesquisa, tendo como enfoque os valores indenizatórios e sua destinação, que em regra são encaminhados para os fundos regulados por lei federal, como Funda Nacional de M eio Ambiente, mas em sede de direitos individuais homogêneos poderá no processo coletivo ocorrer a partiIha de valores em execução de sentença.

Palavras-chave: Dano. Coletivo. Responsabilidade Civil. M eio ambiente.

ABSTRACT: This work is subject to constitutional protection of the environment and civil jurisdiction of diffuse environmental damage and collective. At first the paper analyzes the protection directed by the Federal Constitution of 1988 for the environment, considering this as a fundamental right inserted into the third dimension of rights, essential to maintain human life and other living beings. Second time investigates the theories of environmental liability without impeding the forms and dispositions of civil penalties. And finally analyzes the collective civil jurisdiction under the bias of the civil action in defense of the environment. The research is strictly bibliographic therefore have as a methodological basis of the doctrine of study, law and jurisprudence, as sources of law, making a qualitative approach, with inductive scientific method, and exploratory Processes of collective civil jurisdiction and environmental diffuse under the constitutional basis is the merit of the research, with the focus on the indemnity values and their allocation, which generally are referred to the funds regulated by federal law, National Fund for the Environment, But 
in place of homogeneous individual rights may occur in the collective process shared values in the sentence execution.

Keywords: Damage. Collective. Liability. Environment.

Sumário: Introdução - 1 A Tutela Constitucional do M eio Ambiente e os direitos Transindividuais - 1.1 Processo histórico e evolutivo da proteção legislativa ambiental - 1.2 Classificação do bem ambiental na CRFB/88 e os instrumentos de proteção - 2 A Responsabilidade Civil Ambiental e o Dano Ambiental - 2.1 Do dano ambiental difuso, coletivo e individual homogêneo - 3 A Jurisdição Civil Coletiva: Abordagem da Ação Civil Pública Ambiental - 3.1 Ações coletivas e o processo coletivo - 3.2 Da lei 7347/85 e o meio ambiente como mérito da ação - 4 Considerações - Referências

\section{INTRODUÇÃO}

A consagração da tutela constitucional e judicial do meio ambiente tem fundamentos históricos, marcados a partir no final do século XIX para XX com a crise ambiental deflagrada em Estocolmo no ano 1972. Neste processo o legislativo brasileiro passou a organizar o Estado de Direito Ambiental com início propriamente na Política Nacional de Meio Ambiente (Lei $6.938 / 81$ ), momento de estruturação de um sistema legal de proteção dos recursos naturais, já que antes a legislação constitucional era esparsa e inespecífica, e as demais devolutas. A partir desde marco legal a Carta Constitucional passou a regular um capítulo específico para tratar do meio ambiente, e em demais artigos de maneira esparsa, sendo assim, considerada a Constituição Ecológica de 1988.

Apesar das disposições legislativas anteriores como a Lei 4.717/65, Lei de Ação Popular (LAP) e a Lei de Ação Civil Pública (LACP), o uso das tutelas processuais civis ambientais intensificaram-se com a chegada do Código de Defesa do Consumidor (CDC - Lei 8.078/90) que conceituou uma modalidade nova de direitos, conhecidos como direitos transindividuais, classificados pela lei como difusos, coletivos e individuais homogêneos, ampliando o campo de atuação dos microssistemas, como Estatuto da Cidade, Estatuto do Idoso, LAP, LACP e demais.

Considerando uma nova forma de tutela processual, os processos de massa, ou coletivos, sob a legitimidade extraordinária do Novo Código de Processo Civil, regulados pelo artigo 18 , tiveram origem no comw on law, direito norte-americano com as chamadas class action e, passaram a sediar judicialmente as reparações de danos ambientais e de interesse coletivo. Desta forma uma pessoa física ou jurídica passou a tutelar em nome próprio direito alheio, sendo direito de uma série de pessoas, pois, as lides ambientais tratam-se em potencialidade de interesses coletivos, difusos e individuais homogêneos.

Sob este viés processual o meio ambiente em sentido amplo e estrito foi elevado à categoria de direito fundamental intensificando a preocupação de tutela deste bem jurídico, por isso a Constituição Ecológica em seu artigo 225, parágrafo 3 o dispôs da tripla responsabilidade ambiental, em que o agente poluidor em caso de ação ou omissão em desfavor do meio ambiente responderá administrativa, criminal e civilmente, compondo esferas indepen- 
dentes de atuação.

Nesta conjectura a análise do dano ambiental em sede destas tutelas processuais civis, ação popular e ação civil pública ambiental é matéria árdua para o jurisdicionado brasileiro, pela justa dificuldade de mensuração do dano ambiental, da valoração do bem jurídico, da ampla dispersão de vítimas em acidentes ambientais, e a complexidade de identificação de seus poluidores, por isso, a responsabilidade civil ambiental se firma na teoria objetiva e do risco integral, em regra geral, com a finalidade de facilitar a investigação e reparação do dano ambiental. Por isso, em regra a culpa e o dolo são afastados do cenário de investigação, bastando a ação/omissão e o dano propriamente dito, sem observar as excludentes de responsabilidade.

Tendo em vista a integridade desta pesquisa o mérito de investigação é a tutela constitucional do meio ambiente e a jurisdição civil coletiva, analisando como o meio ambiente é tutelado processual e civilmente via constituição federal de 1988. Em seu corpo estrutural perfaz-se o conjunto de três premissas fundamentais para pesquisa, iniciando com abordagem da proteção constitucional do bem ambiental, e os direitos transindividuais, em segundo momento um estudo da responsabilidade civil ambiental e as formas de reparação e quantificação do dano ambiental, para assim concluir com o aprofundamento da modalidade de ação coletiva, ação civil pública ambiental.

A metodologia de pesquisa perfaz uma análise do tipo bibliográfica, com uso de diversas fontes do direito, em especial a jurisprudencial, de abordagem qualitativa, e com método científico indutivo. 0 objetivo da pesquisa é investigar a tutela constitucional ambiental e suas ferramentas processuais civis de proteção ao meio ambiente, no âmbito dos direitos difusos e coletivos, sob o fundamento da magnitude do bem jurídico meio ambiente para vida do homem, e dos demais seres vivos dentro de um sistema destrutivo mundial de produção econômica, e suposto desenvolvimento social, que é o capitalismo.

\section{A TUTELA CONSTITUCIONAL DO MEIO AMBIENTE E OS DIREITOS TRANSINDIVIDUAIS}

A Constituição Federal de 1988 considera o meio ambiente como um direito fundamental encartado em seu artigo 225 , mas, nem sempre foi atribuído a tal bem este valor. Durante muito tempo a desproteção total foi o cenário identificado antes do processo de implementação da Política Nacional de M eio Ambiente, e a atual Constituição Federal. Os dispositivos legais anteriormente regulamentados eram esparsos, e não atingiam sistematicamente a defesa deste bem jurídico. A fase pós crise ambiental ampliou o interesse e as ferramentas de defesa do meio ambiente, visto atualmente em seu caráter transindividual, integrando a classificação de um direito difuso, coletivo ou individual homogêneo.

\subsection{PROCESSO HISTÓRICO E EVOLUTIVO DA PROTEÇÃO LEGISLATIVA AM BIENTAL}

De acordo com SIRVINSKAS (2016) historicamente o desenvolvimento da proteção jurídica do meio ambiente no Brasil pode ser dividida em três períodos, partindo-se do período 
que começa com o descobrimento do Brasil (1500) e vai até quase metade do século XX. Essa primeira etapa é chamada de fase da exploração ambiental desregrada, ou, primeiro período. Neste período haviam normas isoladas de proteção aos recursos naturais que se escasseavam na época, como, por exemplo, o pau-brasil, e outros.

Silva (2010) relata que por muito tempo predominou no Brasil a desproteção total, de sorte que norma alguma coibia a devastação das florestas, o esgotamento das terras, pela ameaça ao desequilíbrio ecológico. Não havia um controle sob o uso e aproveitamento dos recursos naturais.

Apesar do período marcante de uso desregrado dos recursos naturais assinalou-se normas esparsas nas Ordenações da Coroa Portuguesa, Manuelinas e Filipinas. Estas eram regulamentos que regiam as regras da Coroa, e previa no livro V, Título LXXVIII, que ao abate de animais somente por malícia, aplicava-se nesses casos a pena de forma perpétua no Brasil. Além do corte de pau-brasil sem autorização da Coroa, tinha como pena o açoite ou degredo, fase de penas físicas. (MILARÉ, 2013). Garcia (2010, p. 152) faz considerações importantes acerca deste período expondo que

Deve-se considerar como o nascimento do Direito Ambiental Brasileiro, o período logo após 1548, quando o governador Geral passou a expedir regimentos, ordenações, alvarás, e outros instrumentos legais. À partir daí a legislação ambiental se desenvolveu, mas só tomou corpo realmente durante o século XVIII, através das cartas de leis ou simplesmente leis, que eram determinação de caráter geral, por tempo indeterminado, muitas vezes confundidas com os alvarás que deveriam ter eficácia por um ano.

Em seguimento ao processo evolutivo da legislação ambiental preceitua Sirvinskas (2016) que o segundo período inicia-se com a vinda da Família Real em 1808, e vai até a criação da Política Nacional de M eio Ambiente em 1981. Este período foi marcado por preocupações pontuais com o meio ambiente, objetivando a sua conservação e não preservação. Surgiu neste perío do a fase fragmentária o legislador procurou proteger categorias mais amplas dos recursos naturais, limitando sua exploração desordenada.

Enlaça Silva (2010) que neste período a concepção privatista do direito de propriedade constituía forte barreira à atuação do Poder Público na proteção do meio ambiente, pois protegia o todo a partir de partes, tutelava-se aquilo que tinha interesse econômico.

Frisa-se que esta fase foi marcada pela instauração da crise ambiental no mundo marcante no final do século XIX para XX, marco divisor de águas na proteção do meio ambiente, período importante para quebra de paradigmas desequilibrados de uso dos recursos naturais.

Para Antunes (2015) a Declaração de Estocolmo representa uma conscientização ambiental mundial, pois anteriormente a este documento, os problemas ambientais haviam sido tratados de forma esporádica concentrando apenas na proteção de determinadas espécies e vegetais. Os principais resultados da Conferência de Estocolmo foram a criação do Programa das Nações Unidas para o M eio Ambiente e a aprovação da Declaração sobre o M eio Ambiente Humano, cujo principal objetivo é a cooperação internacional para a proteção do meio 
ambiente.

A promulgação do Código Civil de 1916 floresceu na República Brasileira a proteção ambiental, destacando-se como primeiros avanços a esta fase as disposições dos artigos 554 e 584 do Código Civil de 1916.

Sirvinskas (2016) esclarece que o terceiro período começa com a criação da Lei de Política Nacional do M eio Ambiente, dando-se ensejo a fase holística, que consistia em proteger de maneira integral o meio ambiente por meio de um sistema ecológico integrado, protegendo as partes a partir do todo.

Constata-se o início da formação do Estado de Direito Ambiental saindo de um estado legislativo de desproteção para um sistema integrativo e articulado de instrumento de tutela do meio ambiente, ampliando-se a visão conceitual do bem jurídico meio ambiente, criando um sistema de órgãos ambientais para gerir a política ambiental com seus princípios, diretrizes e instrumentos.

De fato a defesa do meio ambiente ganhava espaço no texto da Carta Republicana, mas ainda timidamente, pela dificuldade de ainda digerir que bem jurídico seria este, um bem autônomo ou acessório da propriedade? Veementemente é expressiva a ligação do meio ambiente e o processo de desenvolvimento econômico do país, tratar do tema era, e ainda é, de extrema delicadeza para o eixo econômico, pela relação de interdependência que se tem (meio ambiente e desenvolvimento econômico). Estas limitações paulatinamente foram sendo superadas retrógrados paradigmas (SIRVINSKAS, 2016).

Garcia (2010) afirma que foi na Constituição Federal de 1934 que a legislação ambiental passou a ser mais abrangente e vieram a lume o Código Florestal (Decreto 23.793 de 23.01.1934) e o Código de Águas (Decreto 26.643 de 10.7.1934), o Código de Pesca (Decreto lei 794 de 19.10.1938), que trouxe algumas normas protetoras das águas e que foram ampliadas nos artigos 36 a 38 do Código de Pesca baixado pelo Decreto Lei 221, de 28.1.1967.

Silva (2010) explica que as Constituições Brasileiras anteriores à de 1988 nada traziam especificamente sobre a proteção do meio ambiente natural, ademais o artificial. Das mais recentes, desde 1946 apenas se extraía orientação protecionista do preceito sobre a saúde e da competência da União para legislar sobre água, floresta, caça, pesca.

Garcia (2010) elucida que em 1967 teve início a legislação federal com o Decreto Lei 248 de 28.2.1967 que instituiu a Política Nacional de saneamento básico, que se preocupava com a chamada 'poluição da pobreza'. Nesta fase do texto constitucional convém reconhecer que o constituinte passava a entender a relação do homem com meio em que vive, estabelecendo expressando o início de uma relação de dependência, e atribuindo valores humanos ao ainda não reconhecido meio ambiente.

E, então finalmente em 1988 foi promulgada a Carta Republicana atual que é considerada a chamada Constituição Ecológica, que entre todas as citadas é a que mais protege 0 meio ambiente tanto no aspecto natural e artificial, elevou 0 a categoria de bem jurídico independente da propriedade, considerando-o como um direito fundamental.

Fiorillo (2015) destaca que a Constituição Federal de 1988 consagrou de forma nova e importante a existência de um bem que não possui característica de bem público, e muitos 
menos privado, voltado à realidade do século XXI, das sociedades de massa, caracterizada por um crescimento desordenado e brutal avanço tecnológico.

Freitas (2009) relembra que o discurso que proferiu a sessão de 5 de outubro de 1988, o Presidente da Assembleia Nacional Constituinte, o Deputado Ulysses Guimarães afirmou que é consagrador o testemunho da Organização das Nações Unidas de que nenhuma outra Carta no mundo tenha dedicado mais espaço ao meio ambiente do que a que vamos promulgar.

Não há o que olvidar, a Constituição Federal de 1988 é uma das Cartas Políticas mais protetivas do bem jurídico meio ambiente, apresenta extensivo rol de instrumentos de tutela, seja processual ou administrativa, que figuram como fortes ferramentas de controle do processo de exploração desregrada dos recursos naturais. É tão essencial o bem em tela que 0 texto constitucional ambiental reservou um capítulo exclusivo para tratar do meio ambiente, como elucida Freitas (2009, p. 54) "capítulo dos mais modernos, casado à generosa divisão de competências e a tratamento jurídico abrangente". Mas, não foi o único momento do texto constitucional que foi reservado para enaltecer o meio ambiente.

\subsection{CLASSIFICAÇÃO DO BEM AM BIENTAL NA CRFB/88 E OS INSTRUM ENTOS DE PROTEÇÃO}

Quando falamos da classificação do bem ambiental e os instrumentos de proteção constitucional é devido enfatizarmos as formas de disposição pedagógica da matéria de Fiorillo (2015) e Silva (2010), vejamos: Silva (2010) organiza o capítulo VI da Constituição Federal de 1988, expondo que o artigo único 225 divide-se em três momentos, a cabeça do artigo (caput 225, CRFB/88) chamada norma matriz ou norma princípio, o parágrafo 1ํ que são as normas instrumentos e o parágrafo $2^{\circ}$ ao $6^{\circ}$ dispõe sobre as determinações particulares.

De outro modo, de acordo com Fiorillo (2015) o artigo 225 em comento pode ser dividido em quatro partes. A primeira parte aponta como direito de todos o meio ambiente ecologicamente equilibrado, a segunda parte relaciona-se a compreensão do bem ambiental, a terceira parte diz respeito à estrutura finalística do direito ambiental, e o quarto e último ponto é o resguardo do bem ao direito futuro, ou seja, as futuras gerações.

Assim conhecendo a forma de elementares doutrinadores interpretarem o texto constitucional do artigo 225, passemos a conhecer o conteúdo divisório do capítulo VI que nos remete diretamente a classificação do bem ambiental, instrumentos de proteção do bem jurídico, titulares do bem, responsabilidades ambientais e demais. E nota-se observando o escorço histórico e conteúdo do texto constituinte que a Constituição Federal de 1988 recepcionou a Política Nacional de Meio Ambiente (PNMA) que foi instituída em 1981 através da Lei 6938/81, pois, vários instrumentos, e conceitos da lei estão na CRFB/88.

0 primeiro deles é o conceito de meio ambiente, e, de acordo com a Lei 6938/81, 0 artigo 3, I explica que "meio ambiente é o conjunto de leis, condições e influências de ordem física, química e biológica que abriga e rege a vida de todas as suas formas" (BRASIL, Lei № 6.938/1981, art. 3으, inciso I).

0 conceito da Lei de PNM A foi recepcionado pela CRFB/ 88 afinal esta buscou tutelar 0

Planeta Amazônia: Revista Internacional de Direito Ambiental e Políticas Públicas 
meio ambiente natural e artificial, em sentido amplo fauna e flora, mas também o aspecto do meio modificado pelo homem, o meio ambiente artificial compreendendo as edificações públicas e privadas no espaço das cidades, ambos são carecedores de equilíbrio ecológico, pois, tal equilíbrio reflete diretamente na sadia qualidade de vida, elementar constitucional da norma matriz. Assim, meio ambiente passou a compreensão de um conceito neo, onde 0 meio ambiente do trabalho, das cidades, o cultural e 0 digital abrangem 0 conceito deste bem jurídico. (FIORILLO, 2015)

Sanado o conceito do bem jurídico, quem são os titulares do meio ambiente ecologicamente equilibrado? Sirvinskas (2016) assevera que "todos" do artigo 225, da CRFB/88 são os sujeitos determinados e os indeterminados, os primeiros são os brasileiros e estrangeiros residentes no território brasileiro compondo as gerações presentes, e os segundos os mesmos, mas que integrarão as gerações futuras, mesmo não integrando o conceito de vida presente constituem sujeitos do direito ambiental futuro.

Fiorillo (2015) destaca que o alcance constitucional do termo todos, fixado no artigo 225 estaria adstrito ao que estabelece 0 artigo 5ㅇ, no sentido de que brasileiros e estrangeiros residentes no País é que delimitam a coletividade de pessoas, ainda que indefinidas de um critério mais específico, com destaque para uma composição transindividual.

É tão importante salvaguardar que a titularidade deste direito em comento deveria ter sido atribuída expressamente não apenas ao homem, mas também as demais espécies de seres vivos, por isso, há atualmente um projeto de lei $n-351 / 2015$ de autoria do Senador Antônio Anastasia (PSDB-MG) que propõe alterações no Código Civil para incluir os animais entre os bens e estabelecer que eles não são coisas, este inclui no artigo 82 e 83 o seguinte "art. 82 [...] Parágrafo único. Os animais não serão considerados coisas. Art. 83... IV - Os animais, salvo o disposto em lei especial." (SENADO, 2015)

Além desta titularidade do sujeito do bem jurídico em comento, a expressão do texto legal do 225, que expõe que o meio ambiente deve ser ecologicamente equilibrado, segundo Sirvinskas (2016) esta expressão deve ser interpretada conciliando o binômio: desenvolvimento e meio ambiente. Este equilíbrio ecológico não significa a inalterabilidade das condições naturais, mas sim, a harmonia ou a proporção e a sanidade entre os vários bens que compõem a ecologia (populações, comunidades, ecossistemas e biosfera).

Outro ponto de extrema relevância são as classificações atribuídas ao meio ambiente com a Carta Ecológica que elevou tal bem ao padrão de direito fundamental. Mas os direitos fundamentais estão no artigo 5ㅇ, deste diploma, e naquele rol inexiste o meio ambiente, como devemos considerar este como fundamental?

Rodrigues (2006) explica que tal direito integra o rol dos direitos fundamentais do artigo 5o, da Constituição, uma vez que decorre do direito à vida. Na verdade o direito ao meio ambiente ecologicamente equilibrado é o direito à vida, mas em uma dimensão mais sofisticada, porque temos direito a uma vida qualificada, sadia, em um ambiente equilibrado.

Sob a teoria de dimensão de direitos difundida por Bobbio (1992) o meio ambiente está compreendido aos direitos de terceira geração, onde também por ocasião da Revolução Industrial surgiu a sociedade de massa e, por consequência, os conflitos de massa, necessi- 
tando o Estado criar novos direitos para garantir e harmonizar a convivência dos indivíduos considerados em seu conjunto, ou seja, coletivamente. Há aqui uma mudança do enfoque: do individual para o coletivo. Foi neste contexto que surgiram os direitos humanos de terceira geração ou dimensão (direitos coletivos, transindividuais), influenciados por valores de solidariedade (SALLES, 2014).

Ainda em sede de norma matriz há no texto constitucional uma divisão de responsabilidades quanto a conservação e preservação dos recursos naturais entre o Poder Público e a coletividade, então ambos em sede associativa devem resguardar tal bem, o contrário que pensariam que a imposição é apenas do poder público, quando de fato não é, não podemos olvidar que os mecanismos de proteção são bem maiores em relação a este do que a coletividade, como preceitua a Lei de Política Nacional no artigo 9‥

\section{A RESPONSABILIDADE CIVIL AM BIENTAL E O DANO AMBIENTAL}

A construção de uma hidrelétrica é um projeto de grande expectativa social e econômica para uma região, transforma espaços, altera camadas do solo, agride espécies diversas de fauna, inunda extensas áreas atingindo casas, e vegetações, de outro modo gera muitos empregos, gera renda, e obviamente comercializa um produto fundamental para a sociedade, energia elétrica. Rapidamente podemos perceber o sistema paradoxal do processo de desenvolvimento econômico do país, que degrada o meio ambiente, e viabiliza comodidade. Mas, a lesão a fauna e flora quem paga por esta?

A Lei de PNM A explica que o poluidor é responsável pela sua conduta desfavorável ao meio ambiente, destacando que "é o poluidor obrigado, independentemente da existência de culpa, a indenizar ou reparar os danos causados ao meio ambiente e a terceiros, afetados por sua atividade" (BRASIL, Lei ํㅡ 6.938/1981, art. 14, § 1ㅇ). Aqui nasce a responsabilidade civil ambiental, qualificando que qualquer ação ou omissão em desfavor do meio ambiente que externalize resultado negativo, como a poluição, teremos o dano ambiental. (BRASIL, 1981)

\subsection{DO DANO AM BIENTAL DIFUSO, COLETIVO E INDIVIDUAL HOM OGÊNEO}

Sob o fundamento na doutrina pioneira do Direito ambiental Fiorillo (2015) expõe que ocorrendo lesão a um bem ambiental, resultante de atividade praticada por pessoa física ou jurídica, pública ou privada, que direta ou indiretamente seja responsável pela lesão ocorrerá dano ambiental.

Neste mesmo eixo explica-se que o dano ambiental é efeito da externalidade ambiental, é a imposição a todos das consequências negativas da produção econômica que traz lucros a particulares. É o uso privado de bens naturais, o dano causado a eles prejudica a todos, de maneira indeterminada, por não poderem usufruí-los por terem sido danificados (GERENT, 2009).

Então sob o processo de desenvolvimento econômico fundado no capitalismo tem-se a base da geração de danos ambientais, o homem desenvolve e degrada, devasta, não raciona 
ou equilibra a extração dos recursos naturais, extrai desmedidamente e assim vai montando o cenário de ecocídio.

0 poluidor pagador denota a responsabilidade do agente sob a sua ação negativa em desfavor do meio ambiente. 0 princípio do poluidor-pagador preconiza um duplo aspecto: preventivo e repressivo. 0 primeiro visa a evitar o dano ambiental, impondo o dever de prevenir danos ao meio ambiente, através do uso de todos os equipamentos e meios necessários. 0 repressivo, a reparação do dano (SIRVINSKAS, 2016).

No que tange a reparação do dano ambiental tem-se este como um gênero amplo que abarca algumas espécies, como o dano ambiental difuso que discute a lesão ambiental a pessoas indeterminadas, ou indetermináveis, e o coletivo pleiteia a grupo ou uma classe de pessoas determinadas ou determináveis, em contraposição o individual homogêneo é pleiteado em esfera subjetiva, e individual é direito divisível. Tais espécies de danos ambientais podem pleitear em sede processual tanto a reparação moral ou material, sem obstar a lesão a flora e a fauna (FIORILLO, 2015).

Claro, que estes conceitos versados não são encontrados em uma legislação ambiental, a classificação destas espécies de danos advém de uma modalidade nova do direito denominado "metaindividuais" ou "transindividuais", aqueles direitos que transpõe-se ao universo da individualidade, como 0 ar que respiramos, a água que alimenta todas as vidas. Assim encontramos o fundamento e conceito de tais direitos no CDC, de acordo com o artigo 81, parágrafo único e incisos. ${ }^{1}$ (BRASIL, 1990)

Para Mazzilli (2015) os interesses transindividuais estão situados entre o público e 0 privado, numa posição intermediária, também chamados de coletivos, que são compartilhados por grupos, classes ou categorias de pessoas (como os funcionários de uma mesma empresa que sofrem contaminação por insalubridade do ambiente, ou o grupo de armadores de pesca que são lesados por vazamento de petróleo). São interesses que excedem o estritamente individual, mas não chegam a constituir o interesse público.

Interessante voltar por um momento no tempo e relembrar as raízes processuais destes interesses metaindividuais, então desde o século XVII por influência do direito norteamericano, através das class action, que eram ações que uma pessoa conseguia pleitear o direito de um grupo, englobando os direitos de todos que estivessem envolvidos no litígio, para que a questão fosse tratada de maneira uniforme, evitando-se assim, a multiplicação de procesSOS (LEAL, 1988).

0 dano coletivo é espécie que mais discute-se em sede de tutela processual ambiental, podendo ser amplamente discutido por ação civil pública ambiental, e ocorrerá quando há um grupo ou classe de pessoas determinadas lesadas por um acidente ecológico. É o caso de

\footnotetext{
${ }^{1}$ Art. 81. A defesa dos interesses e direitos dos consumidores e das vítimas poderá ser exercida em juízo individualmente, ou a título coletivo. Parágrafo único. A defesa coletiva será exercida quando se tratar de: I - interesses ou direitos difusos, assim entendidos, para efeitos deste código, os transindividuais, de natureza indivisível, de que sejam titulares pessoas indeterminadas e ligadas por circunstâncias de fato; II - interesses ou direitos coletivos, assim entendidos, para efeitos deste código, os transindividuais, de natureza indivisível de que seja titular grupo, categoria ou classe de pessoas ligadas entre si ou com a parte contrária por uma relação jurídica base; III - interesses ou direitos individuais homogêneos, assim entendidos os decorrentes de origem comum
}

Planeta Amazônia: Revista Internacional de Direito Ambiental e Políticas Públicas 
armadores de pesca (grupo) que foram prejudicados com a construção da barragem de Itá (Usina hidrelétrica de Itá em Chapecó-SC), a obra acarretou grave alteração no equilíbrio ecológico da região atingida, gerando mortandade de peixes, deslocamento dos mesmos para locais distantes, diminuição da pesca e, consequentemente, dos rendimentos das pessoas que sobrevivem dessa atividade, está demonstrada a culpa da empresa concessionária e 0 seu dever de indenizar os pescadores prejudicados pela construção. (BRASIL, TJ-SC - AC: 149120 SC 2003.014912-0, Relator: Maria do Rocio Luz Santa Ritta, Data de Julgamento: 15/08/2006, Primeira Câmara de Direito Civil, Data de Publicação: Apelação Cível de Chapecó.)

Acerca do dano ambiental difuso Antunes (2015) enfatiza que este é o dano de preocupação fundamental, seja ambiental ou ecológico. Em geral, ele é causado por uma multiplicidade de fontes, uma infinidade de atividades, e de pessoas, principalmente, por atividades que são realizadas nos marcos da atividade econômica legalizada. E, esta quantificação de pessoas é a característica marcante desta espécie, pois tais pessoas são indetermináveis, afinal como quantificarmos agora as pessoas que precisam do ar puro para viver? É difícil chegarmos a esta quantificação, mas o dano será difuso quando não pudermos mensurar os lesados e tivermos o meio ambiente como bem jurídico também lesionado, além da sadia qualidade de vida dos seres vivos.

Os direitos individuais homogêneos destacam-se pela divisibilidade do direito lesionado, apesar do legislador não apresentar no artigo 81, parágrafo único do CDC elementos definidores. Entretanto é possível concluir que se trata de direitos individuais, cuja origem decorre de uma mesma causa. Na verdade, a característica de ser um direito coletivo é atribuída por conta da tutela coletiva, à qual esses direitos poderão ser submetidos (FIORILLO, 2015).

Data máxima vênia a dificuldade em processar e julgar os direitos transindividuais, pela carência de Código de Processo Civil Coletivo, ou de capítulo que verse no novo código sobre tal procedimento, desta forma o CDC, e a Lei de ação civil pública são os diplomas essenciais para estruturar tais processos, sem afastar o novo Código de Processo Civil Brasileiro.

Por isso a jurisprudência vem sedimentando algumas lacunas como a ferramenta processual para discussão desta espécie de direito, firmando o entendimento que firmou entendimento no sentido de que o M inistério Público tem legitimidade 'ad causam' para propor ação civil pública quando a controvérsia envolver direitos individuais homogêneos. Assim é possível falar nesta espécie de direitos em sede de liquidação e execução de sentença, onde cada indivíduo ou seus sucessores poderão promovê-la demonstrando o caráter individualizador das ofensas, e por consequência, a divisibilidade do objeto dessa relação. (STF, RE 699.580 AgR/SC. 2a T. Rel. Min. Celso de Mello. J. em 6-8-2-13)

Sem olvidar, a promoção de ações individuais que apreciam o direito individual homogêneos, visto como o dano ambiental reflexo, ou richochete, então, pelo resultado de acidente ecológico o indivíduo é prejudicado, lesionado, podendo qualificar o dano patrimonial ou extrapatrimonial. 0 primeiro basta demonstrar objetivamente a liquidez dos valores, ou seja, o que foi diminuído de seu patrimônio em detrimento o acidente, já o segundo não há valor certo a ser mensurado, pois a dor é subjetiva, é o caso do agricultor que é prejudicado por 
poluição do rio que abastecia sua plantação, Não houve de fato nenhum prejuízo patrimonial direito, mas está impossibilitado de utilizá-lo para a irrigação de sua plantação (SIRVINSKAS, 2016).

\section{A JURISDIÇÃO CIVIL COLETIVA: ABORDAGEM DA AÇÃO CIVIL PÚBLICA AM BIENTAL}

A chegada dos conflitos de massa trouxe a necessidade de ampliação do sistema processual, e como marco inicial desta evolução tem-se a class action na doutrina norteamericana, com origem no direito inglês no Bill of Peace no Século XVII, procedimento no qual era possível propor uma ação ou sofrer uma ação por intermédio de partes representativas (representative parties). Esse sistema contribuiu para a formação do sistema de jurisdição civil coletiva na legislação brasileira, como a inserção da Lei de Ação Popular, Lei de Ação Civil Pública, o Código de Defesa do AP, e a Constituição Federal Ecológica que reconheceu a necessidade de tutela dos direitos metaindividuais, como meio ambiente ecologicamente equilibrado. (BUENO, 1996)

\subsection{AÇÕES COLETIVAS E O PROCESSO COLETIVO}

Desde meados da década de 60, a 90 o país vem despertando para tutela de interesses que fogem a visão de lides concentradas entre "Caio e Tício", ultrapassando a dimensão individualista processual, passou-se a abranger direitos que não são públicos e nem privados, localizados na fronteira de um para o outro, os direitos e interesses transindividuais, como a defesa do meio ambiente, de valores culturais, históricos, relações de consumo, e de saúde pública, bens jurídicos que uma vez lesionados tendem a atingir indivíduos indeterminados, ou grupos e classes determinadas, aqui jaz a necessidade de pleitear a tutela desses direitos através de ações coletivas, instrumentos processuais de massa.

A primeira ação dessa natureza que se tem notícia ocorreu em 1199 na Inglaterra, quando o pároco M artin propôs ação perante a Corte Eclesiástica de Canterbury, em face dos paroquianos de Nuthamstead, reivindicando o direito sobre oferendas e serviços diários (MENDES, 2008).

Simões (2011) explica que as ações coletivas do direito brasileiro tem suas origens nas ações coletivas do direito norte-americano, denominadas class action, derivadas do instituto inglês denominado Bill Of Peace, inicialmente regulamentada em 1842 e alterada em 1938 e 1966. Na Inglaterra, os tribunais de direito não permitiam o litisconsórcio voluntário fundado somente nas questões comuns. Já o tribunal de equidade (que possuía a função de regular situações que o direito não disciplinava de forma adequada), permitia a existência do litisconsórcio facultativo. As cortes de equidade, para evitar a multiplicidade de procedimentos, passaram a exigir que todos os interessados na lide interviessem no processo, sob pena de extinção. A decisão vinculava todos os interessados.

A class action do direito norte-americano pode ser definida como o procedimento em que uma pessoa, considerada individualmente, ou um pequeno grupo de pessoas, enquanto 
tal, passa a representar um grupo maior ou classe de pessoas, desde que compartilhem, entre si, um interesse comum. Seu cabimento restringe-se àquelas hipóteses em que a união de todos que poderiam ser partes em um mesmo processo não é plausível (até porque seu número poderia chegar a milhões) ou porque sua reunião, em um só processo, daria ensejo a dificuldades insuperáveis quanto à jurisdição e à competência (BUENO, 1996)

As ações coletivas que tramitam sob o sistema de processo coletivo questionam os direitos transindividuais, conhecidos difusos e coletivos, advindos da massificação social, da multiplicação dos direitos, e a rebelião de massas, trazendo tais fenômenos a impossibilidade de usar o ortodoxo sistema liberal individualista do Código de Processo Civil e normas afins para dirimir os conflitos de massa (FIORILLO, 2015).

Desta forma, a chegada do sistema processual coletivo ensejou um movimento de descodificação de inúmeras leis no Brasil, o Estatuto da Criança e do Adolescente (Lei no 8.069/90); o CDC (Lei no 8.078/90); o Estatuto do Idoso (Lei no 10.741/03); o Estatuto do Torcedor (Lei no 10.671/03), dentre outras leis; todas em íntima ligação processual com a Lei de Ação Civil Pública (Lei no 7.347/85) (RIBEIRO, 2012).

A edição destas leis/códigos marcam a formação de diversos microssistemas que são organizações legislativas que tutelam especialmente uma classe social, sob um organograma de normas, assim pela hipossuficiência de grupos, e a desproteção legislativa a medida da garantia de direitos nasce com um microssistema jurídico formado por legislações sistematizadas, e confeccionadas diretamente a um grupo/direitos, como exemplo a Lei 10.257/01 que sancionou o Estatuto da Cidade como tutela jurídico, social e ambiental dos M unicípios regulando termos gerais de planejamento municipal para aplicação posterior do Plano Diretor do Município. Ambos baseados incialmente na Política Nacional Urbana da Constituição Federal de 1988.

Em dois anos depois da atual Constituição Federal, o CDC (lei 8.078/90) delineou 0 processo coletivo no Brasil, inserindo a conceituação dos direitos transindividuais, antes desconhecida pelo ordenamento jurídico brasileiro, motivo este de revogação do artigo 10 da Lei 7347/85. Com o suporte de facilitar a aplicação desse peculiar processo, uma comissão de renomados juristas debruça-se desde 2008, na árdua tarefa de elaborar projeto de lei geral do processo coletivo, diploma que pretende substituir a atual LACP, e, ainda estabelecer balizas gerais ao processo coletivo (THOMÉ, 2016).

\subsection{DA LEI 7347/85 E O M EIO AM BIENTE COM O MÉRITO DA AÇÃO}

A PNM A antes mesmo da Lei de Ação Civil Pública e da Constituição Federal de 1988 mencionava a possibilidade do exercício jurisdicional de tutelas coletivas implicitamente, em seu artigo 14, §1으, impondo ao órgão ministerial a função de propor ações de responsabilidade civil com intuito de reparar os danos causados ao meio ambiente. $\mathrm{E}$ como forma de regulamentação especial a LACP foi sancionada em 1985, e ambas recepcionadas pela CRBF/88. (BRASIL, 1981)

Neste sentido a Carta Republicana de 1988 em seu artigo 127, elencou dentre as fun-

Planeta Amazônia: Revista Internacional de Direito Ambiental e Políticas Públicas 
ções do M inistério Público a defesa da ordem jurídica, do regime democrático e dos interesses sociais e individuais indisponíveis, recepcionando a tutela de direitos transindividuais objeto da anterior Lei de Ação Civil Pública, e de forma direta no artigo 129, impôs a este órgão o ministério de promoção do inquérito civil e a ação civil pública, para "proteção". (BRASIL, CRFB/1988)

E em seguida em 1985 foi sancionada a Lei 7.347/LACP com finalidade de tutelar direitos de massa, mas, apesar do tratamento especial muitas lacunas foram identificadas, como ausência de um conceito de diretos e interesses transindividuais, por isso 0 artigo $1, \underline{0}$, da LACP foi revogado. Então sob ausência deste conceito somente em 1990 que o CDC consolidou os conceitos, de direitos difusos, coletivos e individuais homogêneos em seu artigo 81, alterando assim a LACP e melhorando a aplicação da norma. (BRASIL, 1990)

A ação civil pública ambiental, de acordo com 0 artigo 3, da Lei 7.347/85 dispendia ao bem jurídico protegido a tutela necessária, condizendo com a forma sancionatória prevista na própria lei, como o cumprimento das obrigações de fazer, ou de não fazer, sem obstar as espécies sancionatórias pecuniárias, como as indenizações, e as multas, tendo a simples e a diária (SIRVINSKAS, 2016).

É clarividente que o resgate do status quo ante é a medida mais necessária e adequada para o dano ambiental, ou seja a aplicação das obrigações de fazer ou não fazer serão a primeira medida sancionatória a ser observada pelo magistrado no momento de constatação do dano ao ambiente, a restauração in natura, a preservação e conservação dos recursos naturais (MACHADO, 2013).

Mas, é de suma importância a abordagem da cumulação sancionatória sob a hermenêutica do artigo 11, da LACP, no artigo usa-se o conectivo ou, no sentido de aplicação não cumulativa das sanções, mas, há entendimento superado dos tribunais no sentido de aceitação da cumulatividade de sanções, podendo uma obrigação de fazer somar-se ao pagamento indenizatório. Então, 0 artigo 3ํ, da LACP que preceitua, "a ação civil poderá ter por objeto a condenação em dinheiro ou o cumprimento de obrigação de fazer ou não fazer." (BRASIL, Lei no 7.347/ 1985, art. 3ㅇ), na aplicação da norma deve-se compreender que a insuficiência da restauração in natura ocasionará a reparação pecuniária abstratamente, na visão superveniente da decisão.

As condenações em pecúnia na ação civil pública ambiental recebem o tratamento dado pelo artigo 13, da LACP, onde a indenização, as multas são revertidas a um fundo gerido por um Conselho Federal, ou Estadual de que participarão necessariamente o M inistério Público, e representante da comunidade, sendo seus recursos destinados à reconstituição dos bens lesados. Na ocasião trata-se do Fundo de Defesa dos Direitos Difusos (FDDD) regulados pela Lei 9.008/95. (BRASIL, 1985)

A Ação Civil Pública de Indenização por Dano Material e Moral Coletivo Causado ao Meio Ambiente movida pelo Ministério Público do Estado do Pará, contra pessoa física por transporte de 12.803 metros cúbicos de madeira em tora, sem a devida cobertura legal, isto é, sem a necessária Autorização de Transporte de Produtos Florestais (ATPF) gerou a condenação de obrigação de fazer, em ocasião o reflorestamento da área degradada ou de outra 
apontada pelo IBAM A, e em caso de impossibilidade de cumprimento fixou a título de dano material coletivo, o valor de mercado da madeira, com cálculo feito na base de metro cúbicos apreendidos, e os dano moral coletivo ajustado em $\mathrm{R} \$ 10.000,00$ (dez mil reais) a serem remetidos ao Fundo Estadual de Direitos Difusos. (BRASIL, TJPA, 2014)

De acordo com Fiorillo (2015) o fundo criado pela LACP, está moldado ao instituto norte-americano fluid recovery, as deste se diferencia, pois, no Brasil, o montante pecuniário arrecadado pelo fundo só é quantificado e, fase de liquidação de sentença, fato que não ocorre no sistema norte-americano, uma que nas class action o juiz desde logo quantifica a indenização pelos danos causados.

Acerca dos direitos difusos e coletivos é cediço que os valores pecuniários são endereçados ao FDDD, mas como tratar dos direitos individuais homogêneos? A ação civil pública não se presta somente à defesa dos direitos difusos ou coletivos, mas também à tutela dos interesses e direitos individuais homogêneos, o CDC instituiu a ação coletiva, artigo 81, parágrafo único, nesta ação as vítimas e seus sucessores serão beneficiados, podendo proceder à liquidação e à execução da decisão (FIORILLO, 2015).

0 rol de legitimados à propositura da ação civil pública está elencado no artigo 50 exaustivamente, como M inistério Público, Defensoria Pública, Associações, e demais. Mas, pode-se afirmar que o Ministério Público ocupa papel de maior destaque no cenário jurídico nacional na defesa de interesses supraindividuais, sendo responsável pelo ajuizamento de $90 \%$ das ações civis públicas na defesa do meio ambiente, isto se deve também ao cenário de imposição constitucional e infraconstitucional ao órgão ministerial. Na ação coletiva podemos encontrar no artigo 82, parágrafo único do CDC (CAPPELLI, 2003).

0 inquérito civil é instrumento facultativo, e administrativo, com a finalidade de coletar informações relacionadas ao evento danoso ao meio ambiente, não é um instrumento indispensável para o exercício da ação civil pública em defesa do ambiente, mas, inegavelmente tem auxiliado na preparação dessa ação perante o Judiciário (M ACHADO, 2013).

Ressalta-se que nem todos os legitimados para ajuizar a ação civil pública poderão celebrar o compromisso de ajustamento de conduta. Apenas, os órgãos públicos (M inistério Público, Administração direta e indireta, e Defensoria Pública) são legitimados para tanto. Logo, as associações privadas não podem firmar o referido compromisso (THOMÉ, 2016).

A prescrição das ações civis que versem sobre o dano ambiental sofreram alterações após 0 artigo 225, da Constituição Federal, uma vez que a jurisprudência ${ }^{2}$ e a doutrina vêm interpretando que a responsabilidade da reparação civil é imprescritível, conforme destaca Thomé (2016, p. 648) "a ação civil pública visa reparar o dano ambiental e deve ser protegida pelo manto da imprescritibilidade." Não há óbices para este entendimento, trata-se de um

\footnotetext{
${ }^{2}$ ADM INISTRATIVO. AM BIENTAL. PROCESSUAL CIVIL. AGRAVO REGIM ENTAL NO RECURSO ESPECIAL. AÇÃO CIVIL PÚBLICA. TERM O DE AJUSTAM ENTO DE CONDUTA. DESCUM PRIMENTO. EXECUÇÃO. CARACTERIZAÇÃO. OBRIGAÇÃO. REPARAÇÃO. DANO AM BIENTAL. IM PRESCRITIBILIDADE. IM POSSIBILIDADE. REVISÃO. ACERVO PROBATÓRIO. SÚMULA 07/STJ. INVIABILIDADE. INTERPRETAÇÃO. CLÁUSULA CONTRATUAL. SÚM ULA 05/ST]. É imprescritível a pretensão reparatória de danos ambientais, na esteira de reiterada jurisprudência deste Superior Tribunal de Justiça, a qual não se aplica ao caso concreto, no entanto, porque a obrigação transcrita em termo de ajustamento de conduta não está configurada dessa forma, segundo o texto do acórdão impugnado [...] (BRASIL, ST]. AgRg no REsp 1466096 RS 2014/0164922-1)
}

Planeta Amazônia: Revista Internacional de Direito Ambiental e Políticas Públicas 
direito fundamental, basilar para a vida, e dignidade da pessoa humana, pode-se exigir a qualquer tempo do poluidor a responsabilidade de reparação, mesmo que este não tenha sido 0 originário da conduta, apenas o responsável atual pelo imóvel, afastando-se a exigibilidade do nexo de causalidade da responsabilidade civil ambiental.

\section{CONSIDERAÇÕES}

A Constituição Ecológica de 1988 por recepção da PNMA regulou o meio ambiente como direito fundamental, essencial para sadia qualidade de vida de todos os seres vivos, e neste diapasão foi reservado um capítulo constitucional para tutela do meio ambiente, disposto no artigo 225, da lex matter, e foi organizado em norma matriz e normas instrumentos estruturando as normas constitucionais ambientais (SILVA, 2010). Mas, além deste capítulo há uma série de dispositivos que regulam a defesa do meio ambiente, esparsamente, é o caso do artigo 170, $\mathrm{VI}$, que condiciona o processo de desenvolvimento econômico a conservação e preservação dos recursos naturais.

E, como forma de controle do uso e exploração ilegal de recursos naturais, e prevenção e repressão dos danos ambientais, diante das falhas dos órgãos ambientais no processo proveito deste bem, a PNM A regulou 0 artigo 14, parágrafo 1으, da PNM A, originando ao Estado de Direito Ambiental a responsabilidade civil ambiental, recebida pela norma maior no artigo 225, § 3으, da CRFB/88, assim "qualquer lesão ao meio ambiente passou a ser objeto de responsabilidade civil ambiental" (BRASIL, CRFB/1988, art. 225, § 3ㅇ).

0 dano ambiental é a lesão ao bem jurídico ambiental perpetrado por uma pessoa física ou jurídica, na modalidade difusa, coletiva ou individual homogênea, podendo embasar-se em reparações morais ou materiais, e ainda viabilizar a cobrança de lucros cessantes, a depender do caso concreto, e da matéria probatória a ser elencada no processo.

Como aplicação sancionatória as reparações danosas ambientais apresentam a preferência das obrigações de fazer e não fazer, em casos de ação civil pública ambiental, podendo sob o fundamento do poluidor pagador, e o princípio da reparação aplicar a reparação natural como forma de resgatar o estado anterior do ambiente, como o reflorestamento, a reinclusão de espécies de fauna, aquática ou terrestre, podendo aplicar-se em lugar diverso do dano, como forma de compensar a lesão ao bem ambiental.

A responsabilidade ambiental é assegurada pela Constituição Ecológica em três níveis de competência, civil, penal e administrativa. A civil concerne a reparação do dano e abrange o conceito de direito metainvindividuais, onde a poluição de um recurso hídrico ou atmosférica tende a atingir pessoas indeterminadas, ou grupo, classe, com pessoas determinadas, ambos classificados como direitos coletivos e difusos.

A ação civil pública ambiental é uma tutela processual civil que possibilita a discussão de direitos e interesses transindividuais, mas com uma série de peculiaridades, desde a legitimidade, até as sanções aplicáveis, conforme as leis que respectivamente as regulam, a primeira tem como autores um rol exaustivo do artigo 5으, tem como sanções obrigações de fazer e não fazer além da reparação dos danos ambientais, imputados na forma de indeniza- 
ções, multas.

Os valores recebidos por condenações de tais tutelas serão encaminhados em sua maioria aos fundos ambientais, FDDD e FNM A, após discussões em juízo para quantificação dos danos ambientais, momento processual que ainda repercute dificuldade, pelo trato específico do bem objeto da lide. $E$, em alguns casos que tratarem-se de direitos individuais homogêneos a ação civil pública poderá em fase de liquidação de sentença transferir esses valores aos lesados do acidente ecológico.

\section{REFERÊNCIAS}

ANTUNES, Paulo de Bessa. Direito Ambiental. 7a Edição, Rio de Janeiro: Lumen Juris, 2015. BOBBIO, Noberto (1909), A Era dos Direitos, Tradução de Carlos Nelson Coutinho, Editora Campus, Rio de Janeiro, 1992.

BUENO, Cassio Scarpinella. As class actions norte-americanas e as ações coletivas brasileiras: pontos para uma reflexão conjunta. Revista de Processo, vol. 82. São Paulo: Revista dos Tribunais, 1996.

BRASIL, Lei no 6.938/1981. Política Nacional do Meio Ambiente (PNMA). Disponível em: http:// www.planalto.gov.br/ccivil_03/leis/_66938.htm. Acesso em: 14.04.2016.

, Constituição da República Federativa do Brasil de 1988. (CRFB/88). Disponível em: www.planalto.gov.br/ccivil_03/constituicao/constituicaocompilado.htm. Acesso em: 12.03.2016.

, Lei 7.347/85. Lei de Ação Civil Pública (ACP). Disponível em: http://www.planalto. gov.br/ccivil_03/leis/L7347orig.htm. Acesso em 14.04.2016.

, Lei 8.078/1990. Código de Defesa do Consumidor (CDC). Disponível em: http://ww w.planalto.gov.br/ccivil_03/leis/LEIS_2001/L10257.htm. Acesso em: 12.04.2016.

, Conselho Nacional de Meio Ambiente (CONAMA). Resolução no 237/ 1997. Disponível em: http://www.mma.gov.br/port/conama. Acesso em: 23.04.2016.

Senado Federal. Brasília, 2015. Disponível em: http://www12.senado.leg.br/hpse nado. Acesso em: 23.04.2016.

, Tribunal de Justiça de Santa Catarina. TJ-SC - AC: 149120 SC 2003.014912-0, Relator: Maria do Rocio Luz Santa Ritta, Data de Julgamento: 15/08/2006, Primeira Câmara de Direito Civil, Data de Publicação: Apelação Cível de Chapecó.

, Supremo Tribunal Federal, STF. RE 699.580 AgR/SC. 2a T. Rel. M in. Celso de M ello. J. em 6-8-2-13.

CAPPELLI, Silvia. Ação civil pública ambiental: A experiência brasileira, análise de jurisprudência. Simposio de Jueces y Fiscales de América Latina. Buenos Aires: 2003.

FIORILLO, Celso Antônio Pacheco. Curso de direito ambiental brasileiro. 7ạ Edição. rev. atual. e ampl. São Paulo: Saraiva, 2015.

FREITAS, Gilberto Passos de. Ilícito Penal Ambiental e Reparação do Dano. São Paulo: Revista dos Tribunais, 2009.

GARCIA, Denise Schmitt Siqueira. Evolução Legislativa do Direito ambiental no Brasil. Bole-

Planeta Amazônia: Revista Internacional de Direito Ambiental e Políticas Públicas 
tim Jurídico. 2010. Disponível em: http://www.boletimjuridico.com.br/doutrina/texto.asp? id =2160. Acesso em: 12.03.2016.

GERENT, Juliana. Liquidação de sentença condenatória por danos ambientais difusos. Processos Coletivos, Porto Alegre, vol. 1, n. 1, 19 out. 2009. Disponível em: http://www.proces soscoletivos.com.br/doutrina/ 18-volume-1-numero-1-trimestre-01-10-2009-a-31-12-

2009/73-liquidacao-de-sentenca-condenatoria-por-danos-ambientais-difusos, Acesso em: 02.06 .2016

LEAL, Márcio Flávio Mafra. Ações coletivas: história, teoria e prática. Porto Alegre: Sergio Antonio Fabris, 1998.

MENDES, Aluisio Gonçalves de Castro. Ações coletivas no direito comparado e nacional: Coleção Temas Atuais de Direito Processual Civil. 2. ed. São Paulo: Revista dos Tribunais, 2008. M ACHADO, Paulo Affonso Leme. Direito Ambiental Brasileiro. 12a Edição. São Paulo: Malheiros, 2013.

M AZZILLI, Hugo Nigro. A defesa dos interesses difusos em juízo: meio ambiente, consumidor, patrimônio cultural, patrimônio público e outros interesses. 28. ed. São Paulo: Saraiva, 2015. MILARÉ, Édis. Direito do Meio Ambiente. 4a Edição, São Paulo: Revista dos Tribunais, 2013. RODRIGUES, Ana. Meio ambiente: um bem juridicamente tutelado. 2006. Disponível em: 〈ttp:// www.jurisway.org.br/v2/dhall.asp?id_dh=10>. Acesso em 24. Nov. 2015.

SALLES, Carlos Alberto de. Execução judicial em matéria ambiental. São Paulo: Revista dos Tribunais, 2014.

SILVA, José Afonso da. Direito Ambiental Constitucional. São Paulo: Edição. Malheiros, 2010. SIMÕES, Bruna. A class action americana. Influência exercida no ordenamento brasileiro. Comparação entre os dois sistemas.. In: Âmbito Jurídico, Rio Grande, XIV, n. 87, abr 2011. Disponível em: বhttp://www.ambito-juridico.com.br/site/index.php?n_link=revista_artigos_ leitura\&artigo_id=9405>. Acesso em maio 2016.

SIRVINSKAS, Luis Paulo. Manual de direito ambiental. 14ạ. Edição. São Paulo: Saraiva, 2016. THOMÉ, Romeu. Manual de Direito Ambiental. 6ạ ed. Salvador: JusPODVIM, 2016.

Artigo recebido em 30 de agosto de 2016.

Aprovado em 07 de fevereiro de 2017. 